\title{
CORRECTION
}

\section{Correction to: Factors influencing the need for recovery in employees with hearing loss: a cross-sectional study of health administrative data}

\author{
Hanneke E. M. van der Hoek-Snieders ${ }^{1}$ (D) $\cdot$ Monique Boymans $^{1} \cdot$ Bas Sorgdrager $^{2} \cdot$ Wouter A. Dreschler $^{1}$
}

Published online: 17 September 2020

๑) Springer-Verlag GmbH Germany, part of Springer Nature 2020

\section{Correction to: \\ International Archives of Occupational and Environmental Health \\ https://doi.org/10.1007/s00420-020-01556-z}

The number 0.0408 should be 0.408 . Table 5 has been corrected in this paper.

The original publication of this article contains typographi-

cal error in Table 5, Row 2.

Table 5 Results of multiple linear regression analysis of factors associated with selfperceived listening effort

\begin{tabular}{llrll}
\hline & Variable & $B$ & $95 \%$ CI & $p$ \\
\hline $\begin{array}{l}\text { Complete case } \\
\text { analysis }\end{array}$ & Constant & 6.78 & $3.77 ; 9.80$ & $<0.001$ \\
$R^{2}=0.408$ & Feeling something should change* & 1.96 & $1.12 ; 2.80$ & $<0.001$ \\
& Binaural hearing loss & 0.01 & $0.01 ; 0.02$ & $<0.001$ \\
& Auditory work demands & 0.19 & $0.12 ; 0.26$ & $<0.001$ \\
& Personal adaptations & -0.05 & $-0.06 ;-0.03$ & $<0.001$ \\
Pooled analysis & Constant & 6.10 & $3.35 ; 8.84$ & $<0.001$ \\
after imputation & Feeling something should change* & 1.82 & $1.03 ; 2.61$ & $<0.001$ \\
$R^{2}=0.431$ & Binaural hearing impairment & 0.01 & $0.01 ; 0.02$ & $<0.001$ \\
& Auditory work demands & 0.20 & $0.14 ; 0.26$ & $<0.001$ \\
& Personal adaptations & -0.05 & $-0.06 ;-0.03$ & $<0.001$ \\
\hline
\end{tabular}

*Reference category $=$ not feeling that something should change in the work situation

Publisher's Note Springer Nature remains neutral with regard to jurisdictional claims in published maps and institutional affiliations.

The original article can be found online at https://doi.org/10.1007/ s00420-020-01556-z.

\section{Hanneke E. M. van der Hoek-Snieders}

h.e.vanderhoek@amsterdamumc.nl

1 Amsterdam UMC, Department of Clinical and Experimental Audiology, University of Amsterdam, Meibergdreef 9, 1105 AZ Amsterdam, The Netherlands

2 Amsterdam UMC, University of Amsterdam, Netherlands Centre of Occupational Diseases, Coronel Institute AmCOGG, Meibergdreef 9, Amsterdam, The Netherlands 